\title{
Steady State Characteristics of Active-Clamped Full-Wave Zero-Current-Switched Quasi-Resonant Boost Converters
}

\author{
E. Firmansyah ${ }^{1}$, S. Tomioka ${ }^{2}$, S. Abe ${ }^{1}$, M. Shoyama ${ }^{1}$, and T. Ninomiya ${ }^{3}$ \\ ${ }^{1}$ Dept. of EESE, Grad. School of ISEE, Kyushu University, Kyushu, 819-0935, Japan \\ ${ }^{2}$ SPS R\&D Div., TDK-Lambda Corporation, Kyushu, 813-0017, Japan \\ ${ }^{3}$ Energy Electronics Lab., Faculty of Eng., Nagasaki University, Nagasaki, 852-8521, Japan
}

\begin{abstract}
This proposed boost converter utilizes active-clamp circuit to achieve zero-voltage-switched (ZVS) transition in a full-wave zero-current-switched quasi-resonant (ZCS-QR) converter. The ZCS-ZVS switching transition results in higher efficiency, better output voltage regulation, opens possibility to incorporate higher switching frequency, and has some potency to reduce converter's conducted EMI. It is important to note that the active-clamp circuit works under ZVS condition. Therefore, this switch will not cause excessive losses and extra EMI. In this paper, the working principle and steady state performance of the proposed boost converter are presented. A $100 \mathrm{~V}$ dc input, $300 \mathrm{~W}$ maximum output, and $430 \mathrm{kHz}$ resonant frequency experimental circuit has been built. Maximum efficiency of $95.6 \%$ has been confirmed by experiment.
\end{abstract}

Index Terms: active clamp, boost converter, full-wave ZCS-QR, ZVS

\section{INTRODUCTION}

Boost converter is normally applied to a power factor correction (PFC) circuit for its high performance and simplicity [1]. However, its hard-switching nature rise some issues related to reverse recovery of the catch diode, main switch parasitic capacitance loss, and electromagnetic interference (EMI) problem.

This work is part of an effort in implementing PFC circuit based on full-wave zero-current-switch quasi-resonant (ZCS-QR) technique as an alternative to conventional boost-based PFC. The ZCS-QR technique has been chosen as it is claimed to generate less EMI and makes the implementation of higher switching frequency more feasible [2]. Instead of half-wave ZCS-QR, full-wave topology has been selected for its consistent timing consideration. This makes the converter control effort less demanding.

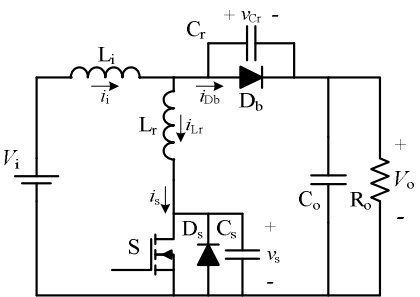

(a)

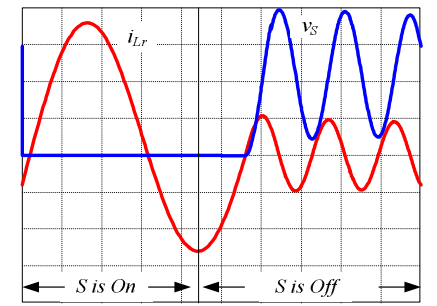

(b)
Fig. 1. (a) The schematic diagram of a conventional full-wave ZCS-QR boost converter and (b) its $v_{s}$ and $i_{L r}$ waveforms under severe ringing voltage.

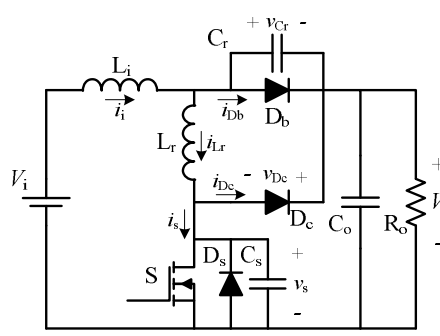

(a)

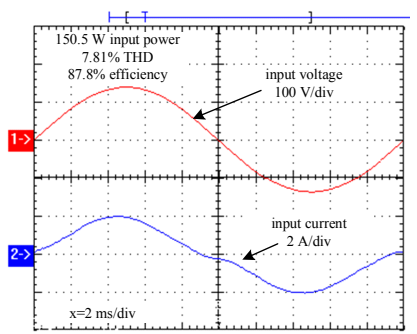

(b)
Fig. 2. (a) Diode-clamped full-wave ZCS-QR boost converter schematic diagram and (b) its performance while implemented as PFC circuit.

Fig. 1. (a) shows the schematic diagram of a conventional full-wave ZCS-QR boost converter. In real application, the main switch $\mathrm{S}$ experiences severe voltage ringing during its turn-off period. This ringing is caused by resonant condition of the switch parasitic capacitance $\mathrm{C}_{\mathrm{s}}$ and the series resonant inductance $\mathrm{L}_{\mathrm{r}}$. Reverse recovery current of anti-parallel diode $D_{s}$ excites this resonant circuit and induces voltage ringing as shown on Fig. 1. (b).

A clamp diode $D_{c}$ has been added to the circuit like shown on Fig. 2. (a) to avoid the ringing problem. The clamped circuit performs well while being implemented as a PFC. The input current waveform of the PFC is depicted in Fig. 2. (b) [3].

After $D_{c}$ has been added to the full-wave ZCS-QR boost converter, switch waveform is free from ringing (Fig. 3. (a)). However, the figure reveals additional troubles those are: (a) high reverse recovery current occurs on $\mathrm{D}_{\mathrm{c}}$ and (b) $i_{\mathrm{Lr}}$ is non-zero during switch turn-on transition. Those problems result in higher losses and more EMI emission.

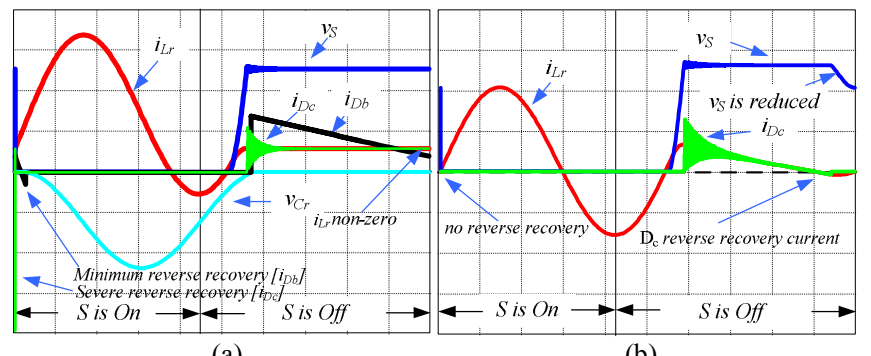

Fig. 3. Diode-clamped full-wave ZCS-QR boost converter's waveforms under very light load condition 


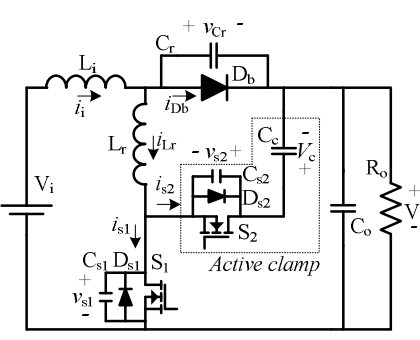

(a)

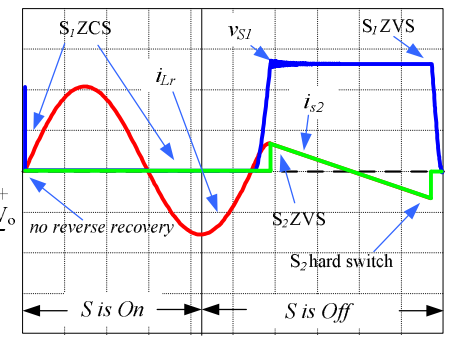

(b)
Fig. 4. (a) The schematic diagram of an active-clamped full-wave ZCS-QR boost converter and (b) its key waveforms.

Fig. 3. (b) shows the diode-clamped topology key waveforms while being lightly loaded. It can be seen that the switch voltage $v_{\mathrm{S}}$ is slightly reduced after reverse recovery current of $\mathrm{D}_{\mathrm{c}}$ ceased. This behavior is similar to an active-clamped technique.

Active clamp technique is known for its capability to avoid voltage ringing while also give additional zero-voltage-switch (ZVS) transition benefit [4]. Therefore, formally applies this technique to a ZCS-QR boost converter results in a ZVS-ZCS switching action.

Theoretically, ZVS-ZCS switching action eliminates switching losses and significantly reduces the electromagnetic interference (EMI) level. Those return in possibility to further increase the converter switching frequency in order to achieve circuit miniaturization while maintaining efficiency.

Furthermore, less filtering effort is required to fulfill the standard requirement as the converter emits less conducted EMI. It gives even further miniaturization and reduces the production cost.

Most soft switching technique applied on PFC incorporates more than one active switch $[5,6,7]$. They also tends to only have ZVS characteristic. Therefore, this new active clamped-full wave-ZCS-boost topology provides improvement by providing ZCS-ZVS capability.

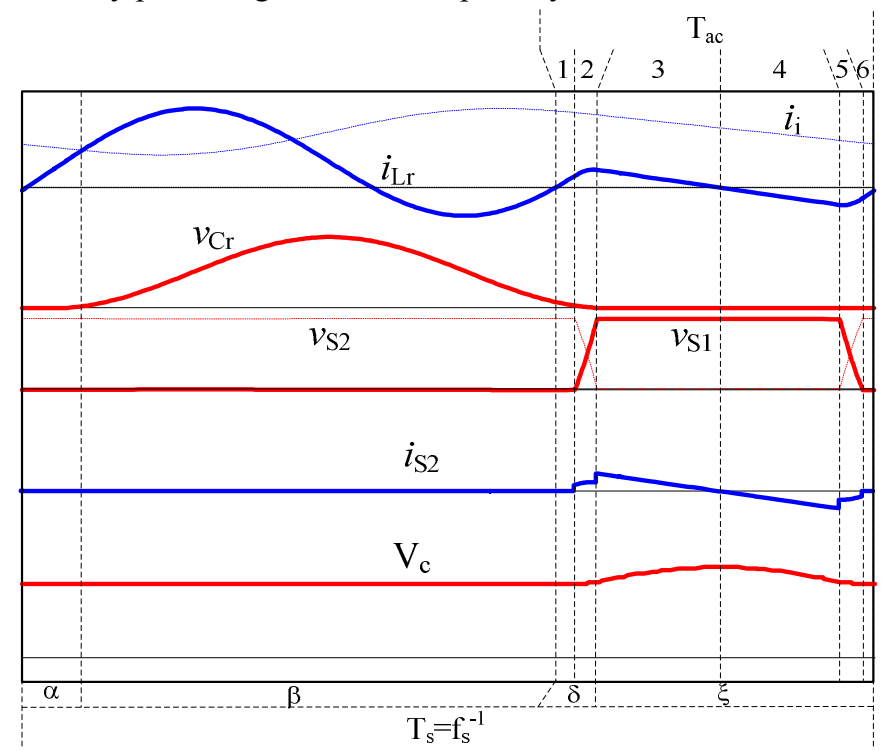

Fig. 5. The active-clamped full-wave ZCS-QR boost converter operation stages

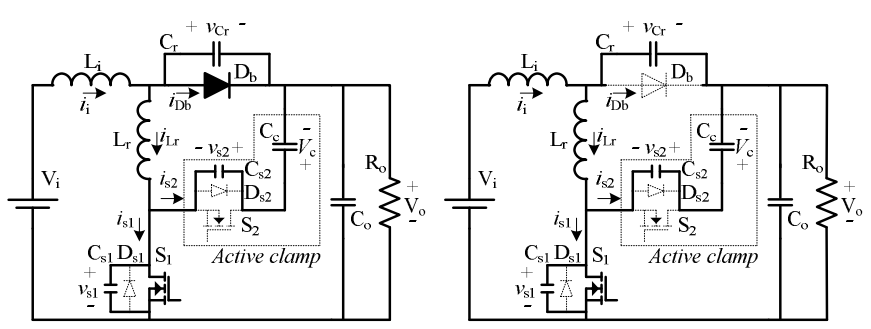

(a)

(b)

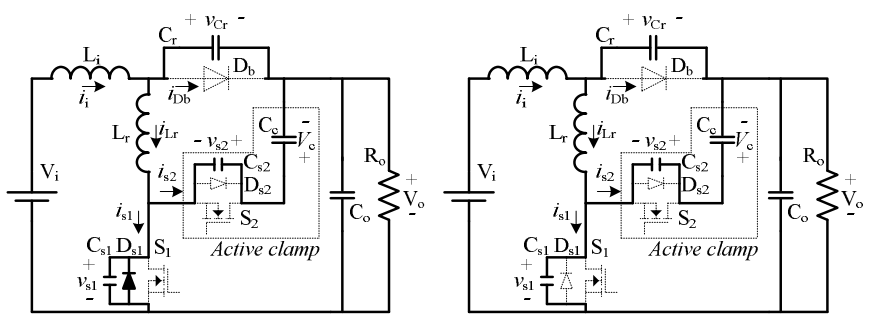

(c)

(d)

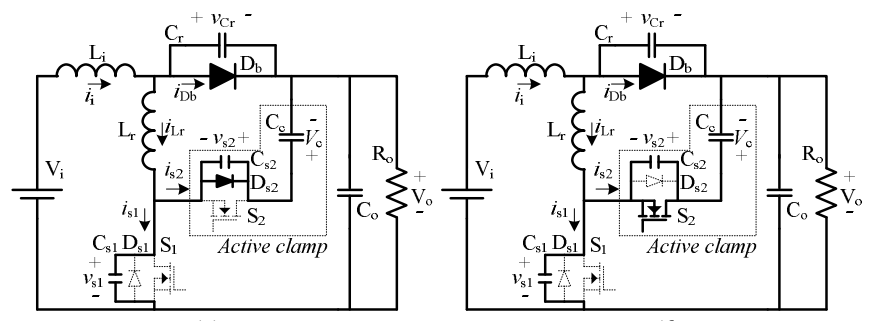

(e)

(f)

Fig. 6. Circuit operation stages of the proposed converter.

\section{The ACtiVe-Clamped Solution}

The proposed active-clamped full-wave ZCS-QR converter is shown on Fig. 4. (a). Impact of active-clamp technique application to the full-wave ZCS-QR boost converter key waveforms could be seen on Fig. 4. (b). It is shown there that no reverse recovery and abrupt current change can be found. It is also evident that $S_{1}$ experiences ZVS condition during its turn-on transition.

The active-clamped converter's operation stages could be analyzed from Fig. 5 and its corresponding circuit configurations shown on Fig. 6. (a) to (f). Generally, the involved process could be classified into two: (a) related to the ZCS-QR switch operation and (b) related to the active-clamp circuit.

\section{The ZCS-QR Switch Operation Stages}

Reference [8] gives detailed expression regarding full-wave ZCS-QR circuit operations. In that reference, all equations are normalized to resonant tank parameters:

$$
\begin{gathered}
f_{0}=\frac{1}{2 \pi \sqrt{L_{r} C_{r}}}=\frac{\omega_{0}}{2 \pi} \\
\omega_{0} t=\theta \\
R_{0}=\sqrt{\frac{L_{r}}{C_{r}}} \\
J_{s}=I_{i} \frac{R_{0}}{V_{o}}
\end{gathered}
$$


Basically, ZCS-QR switch operation is divided by four periods, those are $\alpha, \beta, \delta$, and $\xi$.

Up to the end of $\omega_{0} t=\alpha$, circuit configuration on Fig. 7. (a) occurs. During this period, $\mathrm{S}_{1}$ is turned on. It makes $i_{\mathrm{s} 1}$ increase linearly. This circuit configuration ends when $i_{\mathrm{s} 1}$ equals to $i_{\mathrm{i}}$. Period of $\alpha$ could be determined by:

$$
\alpha=J_{s}
$$

The second period, $\beta$, is the resonant period. During this time, $\mathrm{L}_{\mathrm{r}}$ and $\mathrm{C}_{\mathrm{r}}$ are under resonant condition. Basically, this second period could be divided into positive and negative phase by considering phase of $i_{\mathrm{Lr}}$. The positive phase of $i_{\mathrm{Lr}}$ corresponds to circuit on Fig. 6. (b). While the negative one corresponds to circuit on Fig. 6 . (c). $i_{\mathrm{Lr}}$ equals to zero at the end of this period, that is when $\omega_{0} t=\alpha+\beta$. For a full-wave topology, $\beta$ can be found by:

$$
\beta=2 \pi-\sin ^{-1}\left(J_{s}\right)
$$

The third period, $\delta$, corresponds to circuit on Fig. 6. (d). During this time, $v_{\mathrm{Cr}}$ is discharged linearly up to zero. $\delta$ can be solved by applying equation (7) below,

$$
\delta=\frac{1}{J_{s}}\left(1+\sqrt{1-J_{s}^{2}}\right)
$$

The last period $\xi$ is inserted in order to regulate average energy value processed by the ZCS-QR switch. The longer $\xi$, the smaller the processed average energy value.

From above explanations, one switching period consists of:

$$
\omega_{0} T_{s}=\alpha+\beta+\delta+\xi=2 \pi \frac{f_{0}}{f_{s}}=2 \pi \frac{1}{F_{s}}
$$

Where, $f_{\mathrm{s}}$ is the switching frequency and $\mathrm{F}_{\mathrm{s}}$ is

$$
F_{s}=\frac{f_{s}}{f_{0}}
$$

Maximum switching frequency is

$$
\omega_{0} T_{s} \geq \alpha+\beta+\delta=J_{s}+\left(2 \pi-\sin ^{-1}\left(J_{s}\right)\right)+\left(\frac{1}{J_{s}}\left(1+\sqrt{1-J_{s}^{2}}\right)\right)
$$

Those timing considerations can be used to define a dimensionless variable $\mu$ as equivalent of duty cycle D that normally used in PWM converter. In order to define $\mu$, it is important to determine the average value of $i_{\mathrm{Lr}}$. Fig. 5 shows that the ZCS-QR switch process the energy only during $\alpha$ and $\beta$ period. Therefore, the average value of $i_{\mathrm{Lr}}$ is defined as:

$$
\left\langle i_{L r}(t)\right\rangle_{T_{s}}=\frac{1}{T_{s}} \int_{t}^{t+T_{s}} i_{L r}(t) d t=\frac{q_{1}+q_{2}}{T_{s}}
$$

Where $\mathrm{q}_{1}$ is the energy processed on period $\alpha$ and $\mathrm{q}_{2}$ on pe$\operatorname{riod} \beta$. From this, $\mu$ ideally will be:

$$
\mu=\frac{\left\langle i_{L r}(t)\right\rangle_{T_{s}}}{i_{i}} \approx F
$$

As $\mu$ is a direct equivalent of $\mathrm{D}$, boost converter steady state transfer function can be approximated by,

$$
\frac{V_{o}}{V_{i}}=\frac{1}{1-\mu}
$$

\section{The Active-Clamp Circuit Operation Stages}

In an ideal circuit, current on $\mathrm{S}_{1}$ ceased completely at the end of $\beta$. However, the real circuit realizes reverse recovery current of $\mathrm{D}_{\mathrm{S} 1}$ and finite parasitic capacitance $\mathrm{C}_{\mathrm{s} 1}$. Those two factors make $i_{\mathrm{Lr}}$ rises once more shortly after the end of $\beta$. This additional current makes energy storage on $L_{r}$ not zero. Without any proper reset effort, this energy generates severe voltage ringing.

In the proposed topology, to alleviate voltage ringing problem, the end of $\beta$ is the beginning of the active-clamp circuit operation. The active-clamp operation stages are explained as follows:

During period $1, i_{\mathrm{Lr}}$ raise once more due to reverse-recovery charge $\mathrm{q}_{\mathrm{rr}}$ of $\mathrm{D}_{\mathrm{S} 1}$. This event stores energy as much as $\mathrm{q}_{\mathrm{rr}}$ to $\mathrm{L}_{\mathrm{r}}$. During this period, circuit configuration is still depicted by Fig. 6. (c).

Period 1 over after all $\mathrm{q}_{\mathrm{rr}}$ of $\mathrm{D}_{\mathrm{S} 1}$ being eliminated. It makes the beginning of period 2 where parasitic capacitance $\mathrm{C}_{\mathrm{s} 1}$ and $\mathrm{C}_{\mathrm{s} 2}$ is charged and discharged respectively. The circuit configuration changes to Fig. 6. (d). Charge and discharge currents occur under resonant condition of:

$$
\begin{gathered}
f_{01}=\frac{1}{2 \pi \sqrt{L_{r}\left(C_{s 1}+C_{s 2}\right)}} \\
R_{0_{1}}=\sqrt{\frac{L_{r}}{\left(C_{s 1}+C_{s 2}\right)}}
\end{gathered}
$$

Those occurrences make voltage on $\mathrm{S}_{1}$ increase until reaching $V_{o}+V_{c}$ while voltage on $S_{2}$ decrease up to zero. It is important to note that this incident stores additional energy on $\mathrm{L}_{\mathrm{r}}$ equal to:

$$
q_{c_{s}}=\left(C_{s 1}+C_{s 2}\right)\left(v_{o}+v_{c}\right)
$$

After $S_{1}$ and $S_{2}$ reaches $V_{o}+V_{c}$ and zero respectively, period 2 over and period 3 started. During this period, energy stored on $\mathrm{L}_{\mathrm{r}}$ is dumped to $\mathrm{C}_{\mathrm{c}}$ through $\mathrm{D}_{\mathrm{s} 2}$ under resonant condition of:

$$
\begin{gathered}
f_{0_{c}}=\frac{1}{2 \pi \sqrt{L_{r} C_{c}}} \\
R_{0_{c}}=\sqrt{\frac{L_{r}}{C_{c}}}
\end{gathered}
$$

During period 3, circuit configuration is indicated by Fig. 6 . (e). To take advantages of ZVS condition, $S_{2}$ should be turned-on during this period. Circuit configuration changes to what is shown on Fig. 6. (f) when $\mathrm{S}_{2}$ is turned-on.

After all energy on $L_{r}$ dumped to $C_{c}$, the clamp current $i_{s 2}$ will be zero momentarily. This indicates the beginning of period 4. During this period, if $\mathrm{S}_{2}$ is already turned on, $\mathrm{i}_{\mathrm{s} 2}$ will be flow in opposite direction towards $\mathrm{L}_{\mathrm{r}}$. This current returns under resonant condition like being stated in (17) and (18).

TABLE I

Parameters list of the Proposed ConVerter Prototype

\begin{tabular}{|l|c|c|}
\hline Resonant tank inductor & $\mathrm{L}_{\mathrm{r}}$ & $21 \mathrm{uH}$ \\
\hline Resonant tank capacitor & $\mathrm{Cr}$ & $6.2 \mathrm{nF}$ \\
\hline Resonant tank frequency & $\mathrm{f}_{0}$ & $441 \mathrm{kHz}$ \\
\hline Resonant tank impedance & $\mathrm{R}_{0}$ & $58 \Omega$ \\
\hline Input inductor & $\mathrm{L}_{\mathrm{i}}$ & $220 \mathrm{uH}$ \\
\hline Output capacitor & $\mathrm{C}_{\mathrm{o}}$ & $330 \mathrm{uF}$ \\
\hline Clamp capacitor & $\mathrm{C}_{\mathrm{c}}$ & $520 \mathrm{nF}$ \\
\hline Input voltage & $\mathrm{V}_{\mathrm{in}}$ & $100 \mathrm{~V}$ \\
\hline
\end{tabular}




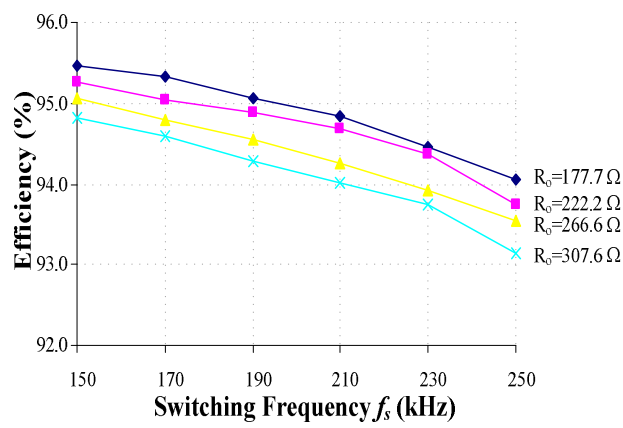

(a)

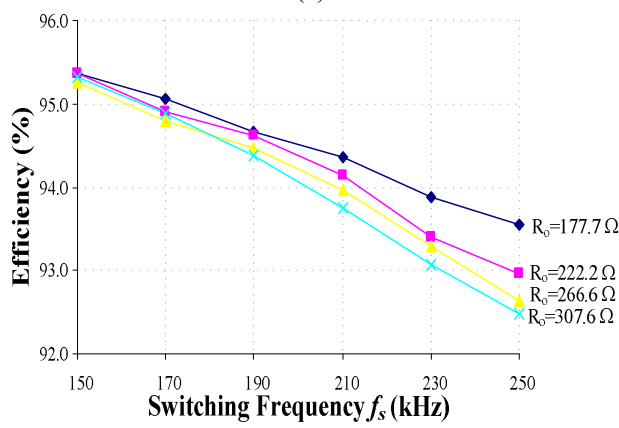

(b)

Fig. 7. Comparison of the converter efficiencies between (a) the active-clamped to (b) the diode-clamped full-wave ZCS-QR boosts converters.

At certain period before the beginning of the next switching cycle, $\mathrm{S}_{2}$ should be turned off. This instance is the beginning of period 5. During this momment, charge on $\mathrm{L}_{\mathrm{r}}$ discharges $\mathrm{C}_{\mathrm{s} 1}$ and charges $\mathrm{C}_{\mathrm{s} 2}$. After all charges on those capacitors discharged and charged respectively, the remaining energy on $\mathrm{L}_{\mathrm{r}}$ will flow through $\mathrm{S}_{1}$ body diode to $\mathrm{C}_{0}$. It is evident here that $\mathrm{S}_{1}$ experiences ZVS transition during next switching cycle as the $\mathrm{C}_{\mathrm{s} 1}$ is already discharged at the beginning of the next switching cycle.

\section{Influence of The Active-Clamp Circuit to $\mu$}

The average value of $i_{\mathrm{Lr}}$ on Fig. 5 during active-clamped period $\left(\mathrm{T}_{\mathrm{ac}}\right)$ can be found by:

$$
\left\langle i_{L r}(t)\right\rangle_{T_{a c}}=\frac{1}{T_{a c}} \int_{0}^{T_{a c}} i_{L r}(t) d t=0
$$

That was because

$$
\left\langle i_{L r}(t)\right\rangle_{T_{a c_{1}}+T_{a c_{2}}+T_{a c_{3}}}=-\left\langle i_{L r}(t)\right\rangle_{T_{a c_{4}}+T_{a c_{5}}+T_{a c_{6}}}
$$

Therefore, it can be concluded here that the active-clamp circuit do not have any influence on $\mu$. Therefore, equation (12) and (13) is still valid in order to calculate ideal steady state transfer function of the proposed boost converter.

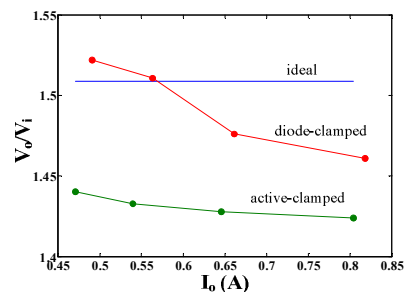

(a)

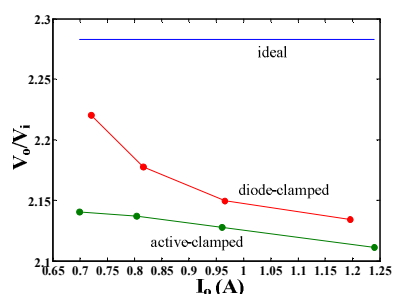

(b)
Fig. 8. The converter's voltage regulation characteristic under (a) $150 \mathrm{kHz}$ and (b) $250 \mathrm{kHz}$ for various loads current

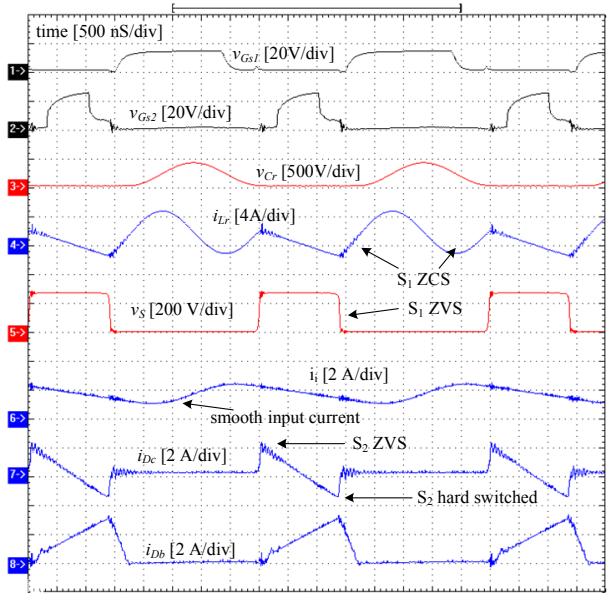

(a)

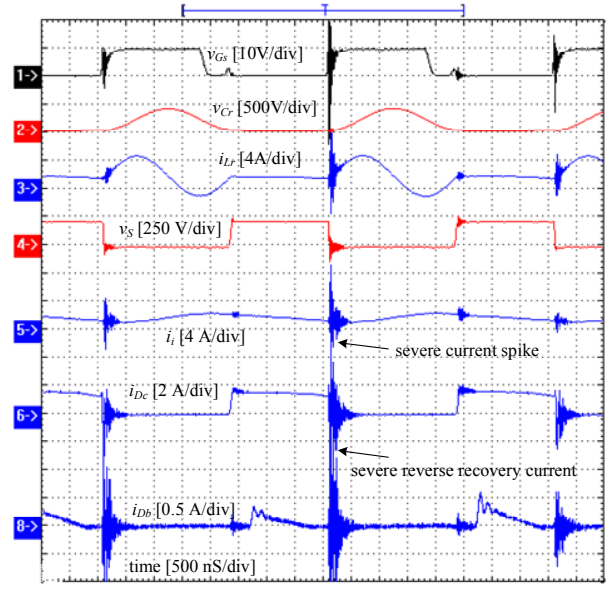

(b)

Fig. 9. Key waveforms comparison between (a) the active-clamped to (b) the diode-clamped full-wave ZCS-QR boost converter.

\section{EXPERIMENTAL RESULT}

Two prototypes with almost identical key parameters have been built to confirm the aforementioned hypothesis. The first prototype is based on diode-clamped topology, while the other one is the active-clamped topology. The specification of key parameters for both converters is listed in Table 1.

\section{Efficiency Comparison}

Fig. 7 shows the efficiency comparison of the active-clamped topology to the former diode-clamped topology. It can be seen that even though the peak efficiency among them are quite similar (95.6\%) but the proposed topology gives more uniform performance under given operating frequency (150 $250 \mathrm{kHz}$ ) and load range.

It should be pointed out that converter's efficiency at high frequency is better compared to former converter. This higher efficiency is the result of the ZVS condition during $\mathrm{S}_{1}$ turn-on. With ZVS transition, less energy losses due to parasitic capacitance occurs. This capacitance loss it the main source of inefficiency during high-frequency operation [8]. 


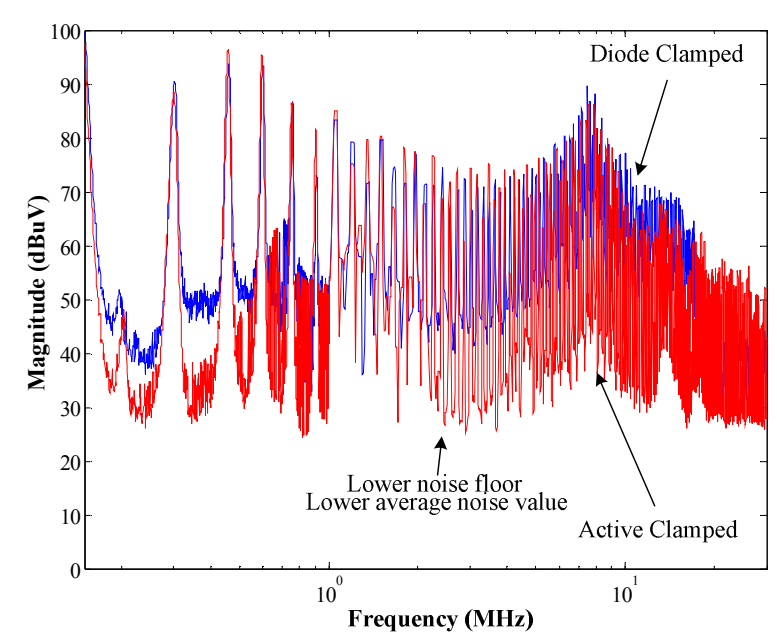

Fig. 10. Conducted EMI characteristics of the proposed converter

However, the proposed converter efficiency under low-frequency and lightly-loaded condition is slightly deteriorated. This is because the active-clamped circuitry provides more parasitic burden compared to the simpler diode-clamped solution stated on [3]. In this operating condition, the advantage of ZVS transition to converter's efficiency is less obvious.

\section{Voltage Regulation Characteristics}

It is important to know about the voltage regulation characteristics of the proposed converter. Fig. 8 depicted that the proposed topology gives better voltage regulation performance compared to former diode-clamped solution. It can be seen that $\mathrm{V}_{\mathrm{o}}$ of the proposed converter only changes in narrow range even $I_{0}$ changes for almost 1 to 2 ratio. However, this figure also indicates that the proposed converter gives more deviation to ideal output voltage $\left(\mathrm{V}_{\mathrm{o}}\right)$.

The real experimental results of the key waveforms are presented on Fig. 9. It is evident that the active-clamped topology gives superior performance to the diode-clamped one in term of waveform transition smoothness. Figures show that the input current $i_{\mathrm{i}}$ of the proposed converter is cleaner compared to the previous converter. There are also no significant oscillations can be found. Also, it has less abrupt changes to be occurred on its voltages and currents waveforms. These better waveforms characteristics are due to less reverse recovery diode problem and ZVS switching action of $\mathrm{S}_{1}$ during its turn-on transition.

\section{Conducted EMI Measurement}

It is also interested to see the effect of smoother key waveforms of the proposed converter in relation to its conducted
EMI characteristics. To reveal that, some EMI measurements have been done by using rohde-schwarz LISN ESH2-Z5. During test, both converters were operated with $100 \mathrm{~V}_{\text {in }}, 330 \Omega$ $\mathrm{R}_{\mathrm{o}}, 150 \mathrm{kHz}$ operating frequency, and without any EMI input filters attached to it. The EMI measurement result can be seen on Fig. 10.

From the figure it is revealed that the proposed boost converter gives lower conducted noise floor. This character contributes towards lower average conducted noise energy. Other than that, at some points, the proposed boost converter also provides lower peak EMI value. Those good points may relax the effort of conduction noise filtering.

\section{CONCLUSIONS}

A topology called active-clamped full-wave zero-current-switched quasi-resonant boost converters has been demonstrated. Its basic operation principles, involved equations, and experimental results have been presented. This new topology has proven to be able to alleviate the voltage ringing phenomena during switch turn-off period on a full-wave ZCS-QR boost converter. Beside that, active clamp circuit also gives additional benefit by adding ZVS characteristic to current converter. It has been shown that this technique performance is better if compared to former simple diode clamp topology in terms of efficiency, voltage regulation, and conducted EMI characteristics. This topology offers good candidate in a boost power factor correction application.

\section{REFERENCES}

[1] ON Semiconductor, Power Factor Correction (PFC) HandbookChoosing the Right Power Factor Controller Solution, Rev. 2, Aug-2004.

[2] Bob Mammano, Resonant Mode Converter Topologies, Unitrode Power Supply Design Seminar, 1991, pp. P3-1 to P3-12.

[3] E.Firmansyah, S. Tomioka, S. Abe, M. Shoyama, T. Ninomiya, Zero-Current-Switch Quasi-Resonant Boost Converter in Power Factor Correction Application, The Applied Power Electronics Conference and Exposition 2009, Washington DC, US, 2009, pp. 1165-1169.

[4] Bill Andreycak, Active Clamp and Reset Technique Enhances Forward Converter Performance, Unitrode Design Seminar-SEM 1000, 1994.

[5] A. Pietkiewicz, D. Tollik, New high power single-phase power factor corrector with soft-switching, INTELEC 96, 6-10 Oct. 1996, Page(s):114 $-119$

[6] Ching-Jung Tseng, Chern-Lin Chen, A novel zero-voltage-transition PWM Cuk power factor corrector, APEC '98. Conference Proceedings 1998., Volume 2, 15-19 Feb. 1998 Page(s):646 - 651 vol.2

[7] Jain, N.; Jain, P.K.; Joos, G.; A zero voltage transition boost converter employing a soft switching auxiliary circuit with reduced conduction losses, Power Electronics, IEEE Transactions on, Volume 19, Issue 1, Jan. 2004 Page(s):130 - 139

[8] R. W. Erickson, D. Maksimovic, "Chapter 20 : Soft Switching", in Fundamentals of Power Electronics, second edition, Massachusetts: Kluwer Academic Publishers, 2001. 